\title{
A comparison of the physico-chemical and phytochemical parameters of glands/hairs of fruits and leaves of Mallotus philippensis (Lam.) Muell. Arg. grown in Sri Lanka
}

\author{
H.G.S.P. Hewageegana ${ }^{1 *}$, L.D.A.M. Arawwawala ${ }^{2}$, M.H.A. Tissera ${ }^{3}$, H.A.S. Ariyawansa ${ }^{1}$ and \\ I. Dhammaratana ${ }^{4}$ \\ ${ }^{1}$ Department of Nidhana Chikitsa, Institute of Indigenous Medicine, University of Colombo, Rajagiriya. \\ ${ }^{2}$ Industrial Technology Institute, No 363, Bauddhaloka Mawatha, Colombo 07. \\ ${ }^{3}$ Gampaha Wickramarachchi Ayurveda Institute, University of Kelaniya, Kandy Road, Yakkala. \\ ${ }^{4}$ Department of Sanskrit, Faculty of Social Sciences, University of Kelaniya, Kelaniya.
}

\begin{abstract}
Medicinal oils prepared using glands/hairs of the fruits or leaves of Mallotus philippensis (Lam.) Muell. Arg., are prescribed for dermal problems. Although the glands/hairs of the fruits are mentioned, they are not freely available in the market. It is therefore useful to explore the possibility of using the leaves, which are freely available instead of glands/hairs for the preparation of medicated oils. The present study compares the physico-chemical properties and the phytochemical components in glands/hairs of the fruits and the leaves of M. philippensis.
\end{abstract}

The extractive matter of glands/hairs of the fruits was significantly higher than that of the cold and hot ethanol extractive matter of the leaves. In addition, the amount of extractable matter observed in cold water extracts of glands/ hairs of the fruits and the leaves was very much less than that was found in other extracts. Total ash $(10.9 \%)$ and the acid insoluble ash $(4.5 \%)$ contents of the leaves were significantly higher than that of the glands/ hairs of the fruit. In addition, several important chemical constituents were present in the glands/hairs of the fruits and leaves of M. philippensis. These findings revealed the similarities of the physico-chemical and phytochemical parameters between glands/hairs of fruits and leaves of $M$. philippensis.

Keywords: Mallotus philippensis, physico-chemical parameters, phytochemical studies.

\section{INTRODUCTION}

In Ayurveda, different types of medicinal preparations are used to treat external and internal ailments by utilizing special parts of medicinal plants such as the leaves, seeds, stem, stem bark, flowers, roots etc.. Mallotus philippensis (Lam.) Muell. Arg. (Family: Euphorbiaceae), commonly known as Kampillaka is used for the preparation of oils for skin ailments (Anonymous, 1979). It is a small, much branched tree about $10 \mathrm{~m}$ in height with grey or pale brown rough bark and can be found throughout India and Sri Lanka (Kirtikar \& Basu, 1996). For many years, the roots, bark, leaves and glands/hairs (red powder covering the fruits) of $M$. philippensis have been used in Ayurveda for the treatment of a variety of disease conditions (Jayaweera, 2006).

Decoctions of the bark of $M$. philippensis has been used for typhoid and meningitis (Manandhar, 2000). The glands and the hairs of the fruits are used in the treatment of intestinal worms and also as a purgative. Its oil is used in dermal problems and non healing wounds (Anonymus, 2001). In addition, the leaves are used externally for different types of skin infections and infected wounds (Kirtikar \& Basu, 1996). The glands/ hairs of the fruit mixed with coconut oil is used to dress wounds and burns and the oil of $M$. philippensis cleanses chronic infected wounds. In dermatitis, especially of the oozing type, M. philippensis is considered to be a valuable remedy (Paranjpe, 2005). Further, the alcoholic extract of the fruits of $M$. philippensis possesses significant anticestodal efficacy, which validates its use in folk medicine (Gangwar et al., 2012). Accordingly, M. philippensis is useful in both internal as well as external treatments. 
The glands/hairs of the fruit and the leaves of M. philippensis are recommended for dermal problems in the Sri Lankan Ayurveda Pharmacopoeia (1979; 1985). However, glands/ hairs of the fruits are not available in the market. If the leaves of $M$. philippensis have properties similar to glands/hairs of the fruits it can be used instead of glands/hairs in medicinal preparations for dermal lesions. Therefore, it is useful to identify the similarities and differences in the physico-chemical properties and phytochemical components present in glands/hairs of the fruits and the leaves of $M$. philippensis.

\section{METHODS AND MATERIALS}

Fresh fruits and leaves of $M$. philippensis were collected from the Medicinal Plant Nursery, Haldummulla, Uva Province, Sri Lanka. The plant materials were identified and authenticated by a Scientist at the Department of Botany, Bandaranayaka Memorial Ayurveda Research Institute, Navinna, Maharagama. Hairs and glands of the fruits, collectively known as red powder were collected from shade dried fruits. The leaves were shade dried, crushed and powdered by using a domestic grinder. Both were kept in the air-tight containers until used.

For the preparation of hot water extract, $5 \mathrm{~g}$ of the sample was taken into a conical flask and distilled water $(100 \mathrm{~mL})$ was added. The contents were shaken well and allowed to stand for $1 \mathrm{~h}$. A reflux condenser was attached to the flask and boiled gently for $2 \mathrm{~h}$, allowed to cool and filtered rapidly using a dry filter paper. Then the filtrate was transferred to a round bottom flask and evaporated to dryness under reduced pressure using a rotor vapor and stored at $4{ }^{\circ} \mathrm{C}$ until use.
Hot ethanol extract was prepared using the same procedure described above using $100 \mathrm{~mL}$ of ethanol instead of $100 \mathrm{~mL}$ of water.

For the preparation of cold water extract, $5 \mathrm{~g}$ of the sample was macerated with distilled water $(100 \mathrm{~mL})$ and kept for $48 \mathrm{~h}$ at room temperature $\left(28-30{ }^{\circ} \mathrm{C}\right)$. The extract was filtered and the filtrate was evaporated to dryness under reduced pressure (at $40{ }^{\circ} \mathrm{C}$ ) and stored at $4{ }^{\circ} \mathrm{C}$ until use.

Cold ethanol extract was prepared using the same procedure described above using $100 \mathrm{~mL}$ of ethanol instead of water.

For the determination of physico-chemical parameters using (a) glands/hairs of fruits and (b) leaves of M. philippensis the follwing experiments were carried out according to the methods described in WHO guidelines (2000); water extractable matter (hot and cold), ethanol extractable matter (hot and cold), moisture content, total ash content, acid insoluble ash content and water soluble ash content.

Preliminary phytochemical screening of the (a) glands/hairs of fruits and (b) leaves of $M$. philippensis was carried out using the water extract and the ethanol extract (both hot and cold). The following qualitative phytochemical tests were performed according to the method described by Farnsworth (1996) with some modifications: presence/absence of phenolic compounds, saponins, flavanoids and glycosides.

For the development of thin layer chromatography (TLC) fingerprints for (a) glands/hairs of fruits and

Table 1: Preliminary phytochemical screening studies of Mallotus philippensis (Lam.) Muell Arg. glands/hairs and leaves

\begin{tabular}{|c|c|c|c|c|c|c|c|c|}
\hline $\begin{array}{c}\text { Type of } \\
\text { phytochemicals }\end{array}$ & \multicolumn{4}{|c|}{$\begin{array}{c}\text { Presence or absence of } \\
\text { phytochemicals in glands/ hairs }\end{array}$} & \multicolumn{4}{|c|}{$\begin{array}{l}\text { Presence or absence of } \\
\text { phytochemicals in leaves }\end{array}$} \\
\hline Phenolic compounds & - & $\sqrt{ }$ & - & $\sqrt{ }$ & $\sqrt{ }$ & $\sqrt{ }$ & $\sqrt{ }$ & $\sqrt{ }$ \\
\hline Saponins & $\sqrt{ }$ & - & $\sqrt{ }$ & - & $\sqrt{ }$ & - & $\sqrt{ }$ & - \\
\hline Flavanoids & - & $\sqrt{ }$ & - & $\sqrt{ }$ & - & - & - & - \\
\hline Tannins & - & $\sqrt{ }$ & - & $\sqrt{ }$ & $\sqrt{ }$ & $\sqrt{ }$ & $\sqrt{ }$ & $\sqrt{ }$ \\
\hline Alkaloids & - & $\sqrt{ }$ & - & $\sqrt{ }$ & $\sqrt{ }$ & $\sqrt{ }$ & $\sqrt{ }$ & $\sqrt{ }$ \\
\hline Coumarin & $\sqrt{ }$ & $\sqrt{ }$ & $\sqrt{ }$ & $\sqrt{ }$ & $\sqrt{ }$ & $\sqrt{ }$ & $\sqrt{ }$ & $\sqrt{ }$ \\
\hline Steroids & $\sqrt{ }$ & $\sqrt{ }$ & $\sqrt{ }$ & $\sqrt{ }$ & $\sqrt{ }$ & $\sqrt{ }$ & $\sqrt{ }$ & $\sqrt{ }$ \\
\hline
\end{tabular}

$\sqrt{ }$ indicates the presence of phytochemicals

HWE - hot water extract; CWE - cold water extract; HEE - hot ethanol extract; CEE - cold

ethanol extract 
(b) leaves of M. philippensis; $50 \mathrm{~mL}$ of methanol was added to $4.0 \mathrm{~g}$ of the sample and stirred well for $30 \mathrm{~min}$. The extract was then filtered through a funnel and the filtrate was concentrated. The TLC fingerprint profile was developed using ethyl acetate: dichloromethane: cyclohexane in a ratio of 0.5:3.5:1 v/v/v. Anisaldehyde was used as the spray reagent.

Data were analyzed by using Mann Whitney test and the findings of $p<0.05$ was considered to indicate statistical significance.

\section{RESULTS AND DISCUSSION}

Results of the preliminary phytochemical screening studies of M. philippensis glands/ hairs and the leaves have been presented in Table 1. Physico-chemical parameters of $M$. philippensis glands/ hairs and the leaves and the TLC fingerprint profiles are shown in Figures 1 and 2, respectively. According to Velanganni and Kadamban (2011), hexane, chloroform and ethanol extractive matter in M. philippensis leaves were 13.0, 9.0 and $10.5 \%$, respectively. However, in the present study, the amount

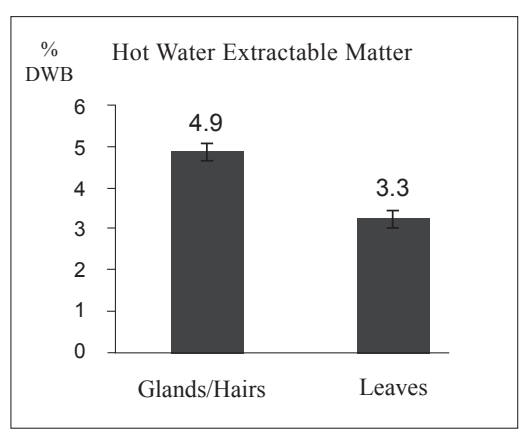

(a)

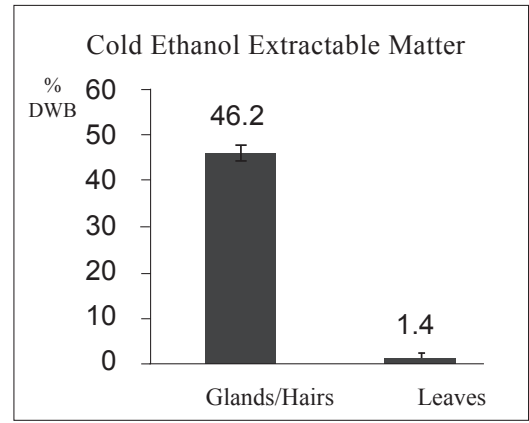

(d)

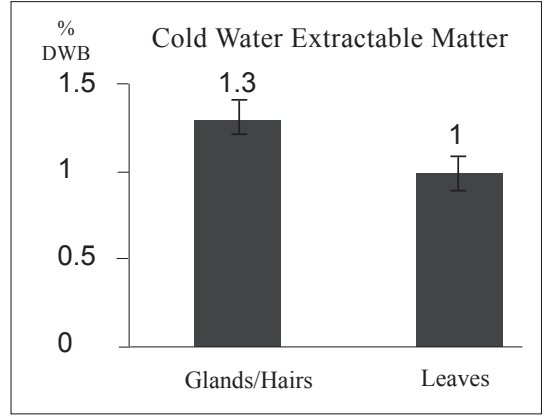

(b)

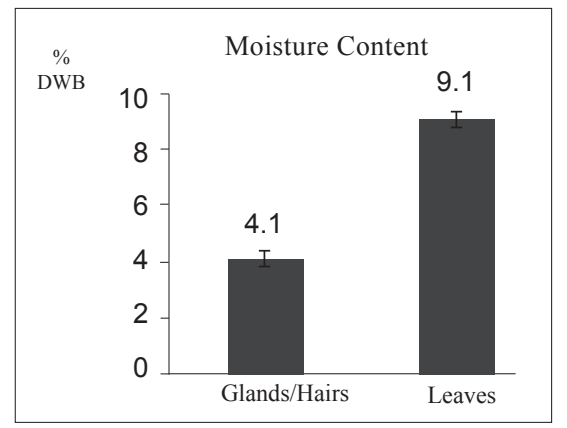

(e)

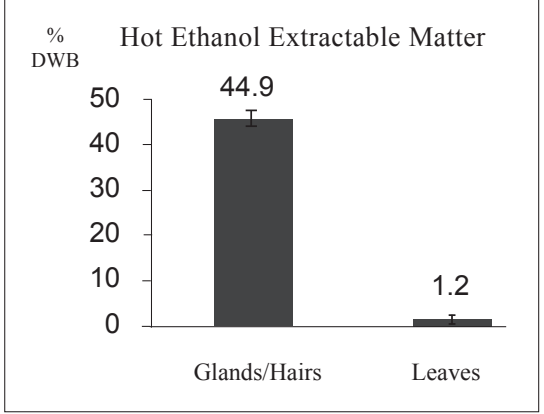

(c)

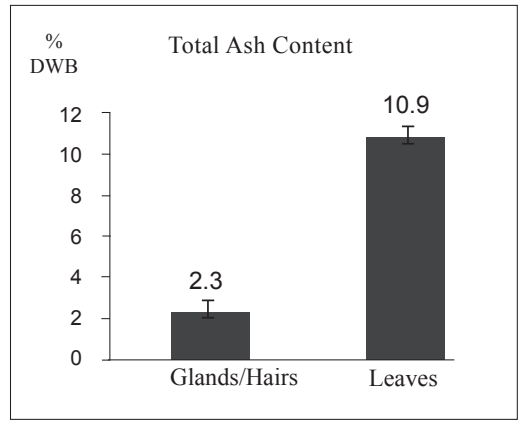

(f)

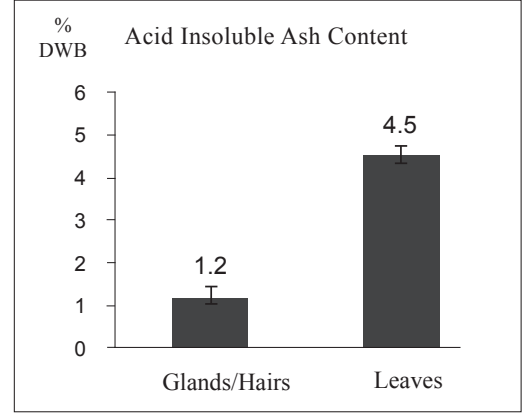

(g)

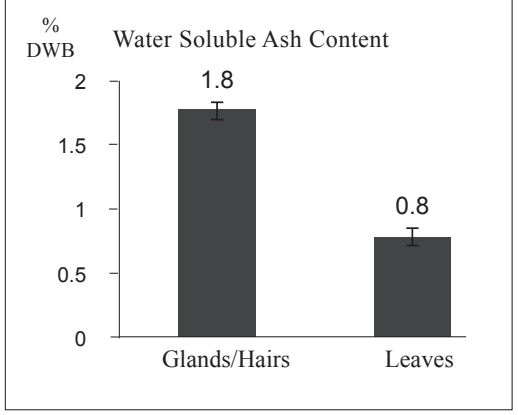

(h)

Figure 1: Physico-chemical parameters of Mallotus philippensis (Lam.) Muell. Arg. glands/hairs and leaves 
of ethanol extractable matter was significantly lower than $10.5 \%$. Furthermore, 15 compounds were identified in the ethanolic extract of $M$. philippensis leaves by the GC-MS technique (Velanganni \& Kadamban, 2011).

The phytochemical constituents of many medicinal plants have been recorded by a number of researchers during the last few decades (Nadkarni, 1976; Sayed \& Mukundan, 2005). Generally, the plant materials were subjected to physico-chemical and phytochemical screening by extracting with various organic solvents.

The extractive value is useful for the evaluation of a crude drug as it gives an idea about the nature of chemical constituents present in the drug. In addition, it is useful for the estimation of chemical constituents soluble in a particular solvent used for extraction (Lincy \& Mathew, 2011). In the present study, the extractive matter of glands/ hairs of the fruit were significantly higher than that of the cold and the hot ethanol extractive matter of the leaves. In comparison with the hot water extract, a much less amount of extractable matter was observed in the cold water extract of glands/hairs of the fruit and the leaves. Therefore, more chemical constituents appear to dissolve in the hot water and ethanolic extracts than the cold water extract. The ash (non aqueous residue that remains after a sample is subject to combustion) consists mostly of metal oxides, salts and inorganic constituents. The ash value is a criterion to judge the identity and purity of crude drugs (Kokate et al., 2006). Acid insoluble ash indicates contamination with silica, for example with earth and sand. Water soluble ash is part of the total ash content, which is soluble in water and is a good indicator of the water soluble salts in the drug (Mukherjee, 2002). Total ash as well as acid insoluble ash content of the leaves of $M$. philippensis was significantly higher than that of the glands/ hairs of the fruit.

The most important bioactive compounds in medicinal plants are alkaloids, flavanoids and phenolic compounds (Devendra et al., 2012). The ethanolic extract of the leaves and the glands/hairs of the fruit of $M$. philippensis revealed the presence of phenolic compounds, tannins, coumarin, steroids, alkaloids and flavanoids. The water extracts of the glands/hairs contained only coumarins, saponins and steroids, while the corresponding extracts of the leaves contained phenolic compounds, tannins and alkaloids, in addition to the above.

Phenolic compounds possess biological properties such as anti ageing, anticarcinogenic, anti inflammatory, anti atherosclerosis, cardiovascular protection and improvement of endothelial function as well as cell proliferation activities (Han et al., 2007). Natural antioxidants mainly come from plants in the form of phenolic compounds such as flavonoids, phenolic acids, etc. (Ali et al., 2008). Tannins interfere with protein synthesis. Flavonoids are hydroxylated phenolic substances known to be synthesized by plants in response to microbial infection and they have been found to exert antimicrobial activities against a wide array of micro organisms in vitro (Marjorie, 1996). The plant extracts in the present study also contained saponins, which are known to produce inhibitory effects on inflammation
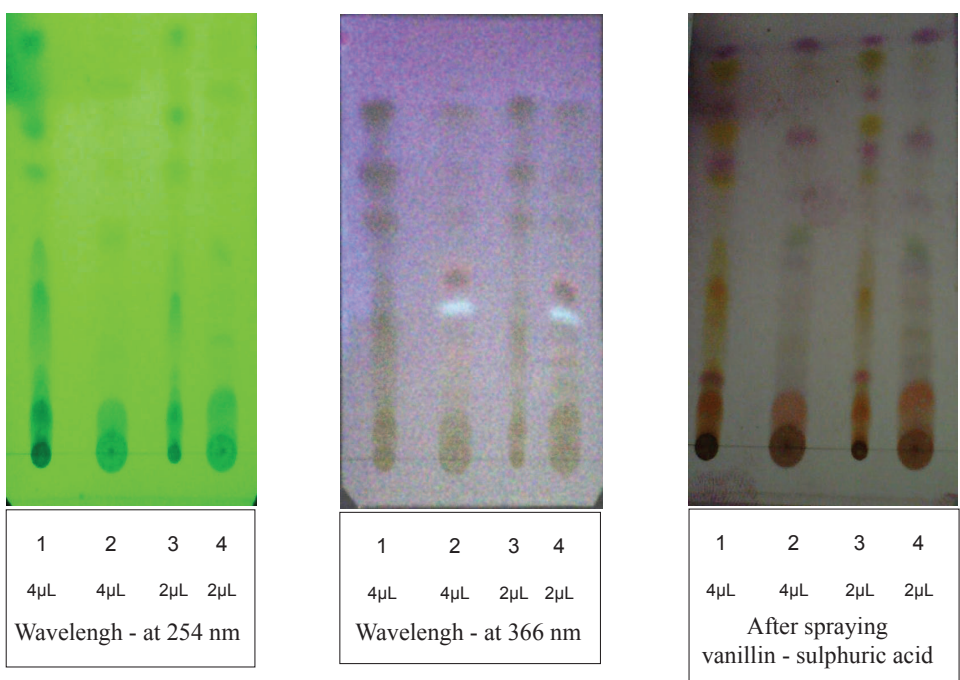

1 and 3 - glands/hairs; 2 and 4 - leaves

Figure 2: TLC fingerprint profiles of Mallotus philippensis (Lam.) Muell. Arg. glands/hairs and leaves 
(Just et al., 1998). Therefore, the presence of various classes of secondary metabolites may play a major role in therapeutic properties of M. philippensis.

The Ayurvedic physicians use the glands/hairs of M. philippensis fruit for internal preparations as well as external preparations such as oils for skin disorders. Although the glands/ hairs of the fruit are preferred, it is not available in the market in Sri Lanka. The present study revealed (a) qualitative similarities in phytochemical constituents in the ethanolic extracts of the leaves and the glands/hairs, (b) some differences in TLC fingerprint profiles and (c) significant differences in the amount of cold and hot ethanol extractable matter of the leaves and the glands/hairs of M. philippensis fruit.

\section{CONCLUSION}

In conclusion, the present study revealed the similarities and differences between the leaves and the glands/hairs of M. philippensis fruit in terms of physicochemical and phytochemical parameters. Moreover, further experiments are needed to (a) quantify the chemical compounds and (b) evaluate bioactivities of the leaves and the glands/hairs of M. philippensis fruit in order to recommend leaves of $M$. philippensis as a substitute to the glands/hairs of $M$. philippensis fruit.

\section{REFERENCES}

1. Ali S.S., Kasoju N., Luthra A., Singh A., Sharanabasava H., Sahuand A. \& Bora U. (2008). Indian medicinal herbs as source of antioxidants. Food Research International 41: $1-15$.

DOI: http://dx.doi.org/10.1016/j.foodres.2007.10.001

2. Anonymous (1979). Ayurveda Pharmacopoeia, volume 1, part 2, p. 49. Department of Ayurveda, Pathiragoda Road, Maharagama.

3. Anonymous (1985). Ayurveda Pharmacopoeia, volume 1, part 2, p. 96. Department of Ayurveda, Pathiragoda Road, Maharagama.

4. Anonymous (2001). Agnivesha-Caraka Samhita, revised by Caraka and Drudabhala, with commentary of Cakrapaneedatta, $5^{\text {th }}$ edition (ed. Jadavji Trikamji). Choukamba Sanskrit Sanstan, Varanasi, India.

5. Devendra B.N., Srinivas N. \& Solman K.S. (2012). A comparative pharmacological and phytochemical analysis of in vivo \& in vitro propagated Clotalaria species. Asian Pacific Journal of Tropical Medicine 5: 37 - 41.
6. Farnsworth N.R. (1996). Biological and phytochemical screening of plants. Journal of Pharmaceutical Science $\mathbf{5 5}$ : $225-276$.

DOI: http://dx.doi.org/10.1002/jps.2600550302

7. Gangwar M., Dalai A., Chaudhary A., Singh T.D., Singh S.K. \& Nath G. (2012). Study on activity of alcoholic extract of glands and hairs of fruits of Mallotus philippensis in murine cestodal infection model. International Journal of Pharmacy and Pharmaceutical Science 4: 643 - 645.

8. Han X., Shen T. \& Lou H. (2007). Dietry polyphenols and their biological significance. International Journal of Molecular Sciences 8: 950 - 988.

DOI: http://dx.doi.org/10.3390/i8090950

9. Jayaweera D.M.A. (2006). Medicinal Plants (Indigenous and Exotic) used in Sri Lanka, pp. 225. M.D. Gunasena \& Co. (Printers) Ltd., Colombo 12.

10. Just M.J., Recio M.C., Giner R.M., Cueller M.U., Manez S., Billia A.R. \& Rios J.L. (1998). Antiinflammatory activity of unusual lupine saponins from Bupleurum fruticescens. Planta Medica 64: 404 - 407.

DOI: http://dx.doi.org/10.1055/s-2006-957469

11. Kirtikar K.R. \& Basu B.D. (1996). Indian Medicinal Plants, volume 3, pp. 2267 - 2268. Vally Offset Printers and Publishers, Dehradun, India.

12. Kokate C.K., Purohit A.P. \& Gokhale S.B. (2006). Text Book of Pharmacognosy, pp. 109 - 133. Nirali Prakashan, Pune, India.

13. Lincy J. \& Mathew G. (2011). Pharmacognostical profiling of Geranium ocellatum leaves. International Journal of Medicinal and Aroma Plants 1: 351 - 354.

14. Manandhar N.P. (2000). Plants and People of Nepal. Timber Press, Portland, USA.

15. Marjorie C. (1996). Plant products as antimicrobial agents. Clinical Microbiology Reviews 12: 564 - 582.

16. Mukherjee P.K. (2002). Quality Control of Herbal Drugs. Business Horizons, New Delhi, India.

17. Nadkarni K.M. (1976). Indian Materia Medica, volume I and II. Popular Prakashan Pvt. Ltd., Mumbai, India.

18. Paranjpe P. (2005). Indian Medicinal Plants - Forgotten Healer, pp. 116. Chaukhamba Sanskrit Pratishthan, Delhi, India.

19. Sayed N.Z. \& Mukundan U. (2005). Medicinal and Aromatic Plants of India, part I (eds. I.A. Khan \& A. Khanum). Ukaaz Publications, Hyderabad, India.

20. Velanganni J. \& Kadamban D. (2011). Phytoconstituents of ethanol extract of Mallotus philippensis (Lam.) Muell. Arg. Var. philippensis (Euphorbiaceae). International Journal of Pharmaceutical Research and Development 3: 73 - 76.

21. World Health Organization (WHO) (2000). General Guidelines for Methodologies on Research and Evaluation of Traditional Medicine. World Health Organization, Geneva, Switzerland. 